\section{MERLEAU-PONTY ENTRE ONTOLOGIA E METAFÍSICA}

Marcus Sacrini A. Ferraz

Resumo: Neste texto, retomamos a avaliação de Michel Haar segundo a qual o projeto ontológico de Merleau-Ponty redundaria em uma metafísica. A fim de tornar tal avaliação mais severa, propomos um outro critério, de inspiração kantiana, conforme o qual a obra de Merleau-Ponty também poderia ser classificada como metafísica. Em seguida, expomos as estratégias filosóficas de Merleau-Ponty com base nas quais julgamos que conforme nenhum desses dois critérios MerleauPonty constitui um discurso metafísico.

Palavras-chave: ontologia, metafísica, Merleau-Ponty, Michel Haar, Heidegger.

Meu principal objetivo neste texto é avaliar as linhas gerais do projeto ontológico final de Merleau-Ponty à luz da crítica de que se trataria de um projeto metafísico. Essa crítica foi apresentada por Michel Haar no impactante artigo intitulado Proximité et distance vis-à-vis de Heidegger chez le dernier Merleau-Ponty (Haar 1, p.9-34). Pretendo explicitar o critério utilizado por Haar para estabelecer tal crítica e questionar se ele realmente se aplica à última filosofia de Merleau-Ponty. Além disso, vou estabelecer um segundo critério para o reconhecimento de uma investigação filosófica como metafísica, para, dessa maneira, submeter a obra de Merleau-Ponty a uma avaliação ainda mais rigorosa que aquela proposta pelo próprio Haar.

A fim de marcar a distinção entre ontologia e metafísica, Haar usa um critério de inspiração heideggeriana: uma empreitada filosófica pode ser qualificada de metafísica se ela toma um ente ou as características próprias a uma classe de entes como definidoras do ser em geral. Nesse caso, o procedimento metafísico se caracteriza pela seleção arbitrária de uma dimensão ôntica como fundante de todas as demais e, em seguida, pela universalização ou hipóstase dessa dimensão, a qual passa então a se apresentar como o próprio ser em geral (Haar 1, p.13, 33).

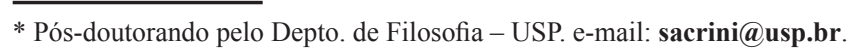

Esse procedimento metafísico seria problemático porque associar o ser a alguns aspectos ônticos mascara a sua complexidade. É verdade que o ser perpassa as dimensões ônticas, faz exatamente com que elas sejam, com que vigorem e se imponham como tais aos sujeitos. Mas o ser não deve ser identificado a nenhuma delas em particular, o que tornaria incompreensível a sua manifestação em todas as dimensões ônticas. Assim, a hipóstase ôntica não respeita as condições inerentes à própria aparição do ser e leva a resultados inconsistentes com a complexidade ontológica do mundo em geral.

Vamos propor agora por nossa própria conta um outro critério para o reconhecimento de uma metafísica, o qual, em certo sentido, complementa aquele fornecido por Haar. Trata-se de um critério de inspiração kantiana, segundo o qual uma empreitada filosófica pode ser qualificada de metafísica se pretende descrever ou explicar realidades que de modo algum figuram na experiência, que excedem as aparências fenomênicas, mas que no entanto poderiam ser apreendidas pela pura concatenação lógica de conceitos. Essas realidades pretensamente descritas seriam aquelas mais fundamentais, quer dizer, aquelas responsáveis pela ordenação e sentido das aparências sensíveis.

Essa pretensão descritiva ou explicativa se revela como problemática se se analisa os instrumentos cognitivos disponíveis aos sujeitos humanos. Parece razoável supor que o conhecimento humano se estabelece com base em e nos limites de uma experiência possivel, o que significa que deve haver uma base sensível, empírica, sobre a qual os conceitos podem atuar. Na ausência de tal base, não se pode legitimamente apresentar a mera ordenação lógica de conceitos como uma descrição ou explicação de realidades. Sem respeitar essa condição, uma investigação filosófica construiria somente hipóteses inverificáveis, as quais jamais se estabeleceriam como verdadeiras apresentações de realidades. Uma investigação filosófica pode então ser qualificada de metafísica se não respeita as condições subjetivas de acesso ao ser (tais como a limitação do conhecimento a uma experiência possível) e, nesse sentido, seus resultados são inconsistentes com as estruturas existenciais-cognitivas da subjetividade humana.

Apresentamos, assim, dois critérios que distinguem o modo metafísico de investigar o ser. Esse modo transgrediria, seja em relação à subjetividade cognoscente, seja em relação ao próprio ser em geral, certas condições constitutivas do problema ontológico, e chegaria invariavelmente a impasses. Por oposição a esse modo metafísico, 
haveria um modo ontológico de investigar o problema do ser. Esse modo ontológico leva em conta as particularidades cognitivas e existenciais da subjetividade e a complexidade da manifestação do ser. Trata-se de uma investigação que não ignora nem como as estruturas existenciais condicionam o acesso ao mundo e nem que a amplitude do ser não se reduz a certas propriedades ônticas.

\section{II}

Nesta seção, pretendo apresentar as principais características daquilo que MerleauPonty apresenta como ontologia, para então, na seção seguinte, avaliar se sua reflexão pode ser caracterizada como metafísica, segundo os critérios estabelecidos acima.

A partir dos anos $50^{1}$, Merleau-Ponty começa a apresentar sua própria empreitada filosófica como aquela de elaborar uma ontologia. Em 1952, no curso intitulado $O$ mundo sensivel e o mundo da expressão, Merleau-Ponty parece já estabelecer as linhas gerais de sua investigação ontológica, embora ainda não a intitule dessa maneira. Em todo caso, podemos distinguir já nesse curso as principais características de sua ontologia tardia. Ali, Merleau-Ponty lamenta que as filosofias da época, embora reconhecessem a originalidade da atividade perceptiva ante as categorias clássicas, não extraíssem dela uma nova noção do ser e da subjetividade. Realizar tal extração passa a ser justamente a meta assumida por Merleau-Ponty, para quem "o filósofo aprende a conhecer, no contato com a percepção, uma relação com o ser que torna necessário e que torna possível uma nova análise do entendimento" (Merleau-Ponty 6, p.11-12). Quer dizer que as descrições da vida perceptiva devem levar a uma reforma do entendimento, isto é, a uma renovação das principais categoriais pelas quais se compreende a experiência e o ser em geral. As categorias clássicas, tais como aquelas de substância, objeto e sujeito não apreenderiam corretamente as articulações do mundo percebido, o qual, se explorado sem a projeção prévia de tais categorias, exige um novo arcabouço conceitual, uma nova ontologia, no sentido de uma compreensão global renovada dos modos de ser das coisas e eventos.

É possível já no curso de 1952-3 reconhecer as duas tarefas filosóficas que Merleau-Ponty apresentará sob o nome tradicional de ontologia. Trata-se, em primeiro lugar, de instituir um contato com o ser, ou seja, de tornar tema filosófico o âmbito em que se estabelece um convívio com dimensões ontológicas que escapam do arcabouço conceitual clássico. Em segundo lugar, e em conseqüência do primeiro ponto, trata-se de formular os recursos conceituais convenientes para exprimir um tal ser assim já atestado por experiência. Notemos que essa tarefa de renovação conceitual permanece facilmente reconhecível, como marca distintiva do trabalho ontológico, mesmo nos textos finais de Merleau-Ponty. Por exemplo, numa nota de janeiro de 1959, o autor afirma que "a ontologia seria a elaboração das noções que devem substituir aquela de subjetividade transcendental, aquelas de sujeito, objeto, sentido" (Merleau-Ponty 3, p.219). Por sua vez, parece que a primeira tarefa, quer dizer, o estabelecimento de um âmbito responsável pelo contato com o ser, muda bastante de figura no decorrer dos anos cinqüenta, como veremos a seguir.

Ainda fortemente marcado pelo legado da Fenomenologia da Percepção, Merleau-Ponty, no início dos anos 50, considera que são os fenômenos percebidos a principal fonte de contato com um ser que escapa às categorias clássicas. É o que fica claro em seu curso $O$ mundo sensivel e o mundo da expressão, analisado brevemente no parágrafo anterior. Porém, no correr da década, o filósofo toma uma gama bem mais ampla de eventos como compondo o ser com o qual se tem contato. Por exemplo, no resumo do primeiro curso sobre a natureza (1956-7), o autor afirma que "se nós não nos resignamos a dizer que um mundo de onde seriam retiradas as consciências não é nada, que uma Natureza sem testemunhos não teria sido e não seria, nos é necessário de algum modo reconhecer o ser primordial que não é ainda o ser sujeito nem o ser objeto, e que desconcerta a reflexão em todos os sentidos" (Merleau-Ponty 2, p.357). Aqui, MerleauPonty almeja descrever o ser primordial, o qual não depende nem mesmo do testemunho da consciência para vigorar e que, assim, não se limita ao ser percebido. Trata-se de buscar um contato com um ser que resistiria mesmo a uma suposta aniquilação da consciência, quer dizer, com um ser que não se restringe ao ser percebido strictu sensu.

No curso A filosofia hoje (1958-9), Merleau-Ponty promove a ampliação final do âmbito de contato com o ser. Não são só fenômenos percebidos particulares e nem mesmo estruturas naturais que nada devem à consciência os componentes do ser, mas também eventos históricos, atividades artísticas e mesmo a situação crítica da cultura contemporânea. Merleau-Ponty comenta: "desvelamento de um tipo de ser diferente 
daqueles em que reside isso que se chama 'matéria', 'espírito', 'razão'. Nós estamos

em contato com esse tipo de ser por nossa ciência e nossa vida privada e pública. Mas ele não tem existência oficial" (Merleau-Ponty 4, p.37). Mas de que maneira a ciência e a vida privada e pública estão em contato com um ser que não é reconhecido oficialmente pelas categorias filosóficas? Para Merleau-Ponty, esse é um dos efeitos mais instigantes de uma crise geral da cultura contemporânea. Segundo o filósofo, em diferentes domínios, seja no que tange à própria coexistência social, seja em relação às expressões artísticas, o conjunto de definições clássicas que fixava a identidade de um domínio e seus procedimentos práticos (por exemplo, a definição da pintura e de como se pinta, ou a definição da sociedade e de como os indivíduos devem nela se comportar) é abalado ante certas situações ou criações contemporâneas. Tal conjunto de definições se mostra então como contingente, quer dizer, não como modo único de se obter resultados artísticos ou de se compreender a sociedade, mas como modelos privilegiados durante certa fase histórica. A crise de tais modelos ante os novos sistemas expressivos e as novas configurações históricas oferece a ocasião para renovar as categorias ontológicas gerais que subjazem a tais modelos.

Atesta-se assim, no decorrer da obra escrita por Merleau-Ponty nos anos 50, uma paulatina ampliação do âmbito em que se pretende obter contato com o ser: primeiramente tratava-se somente do mundo percebido, mas em seguida também se acrescentou o estudo da natureza em geral, e, por fim, os processos histórico-culturais nas quais a vida humana está envolvida. A ampliação é tamanha que Merleau-Ponty chega a apresentar sua ontologia, no curso "A filosofia hoje", de 1958-9, como "consideração do todo e de suas articulações” (Merleau-Ponty 4, p.37). Quer dizer que é em relação a todos os domínios da experiência humana que se deve investigar como há um contato com estruturas ontológicas não abarcadas pelas categorias clássicas (investigação que, por sua vez, deve levar à reformulação das noções mais básicas da filosofia). Vejamos a seguir se esse modo de conceber a reflexão ontológica pode ser classificado de metafísico, no sentido definido anteriormente.
Agora que esboçamos ao menos o projeto geral da ontologia pretendida por Merleau-Ponty, vamos avaliá-la por meio dos dois critérios estabelecidos na primeira parte deste texto. Tomemos primeiramente o critério utilizado por Michel Haar. A principal limitação do projeto de Merleau-Ponty, segundo Haar, é sua obsessão por um mundo sensível apresentado como ser universal. Ao Merleau-Ponty relativizar a prioridade da consciência perceptiva e do corpo próprio, ele o faria em prol do ser concebido como sensibilidade em geral (Cf. Merleau-Ponty 3, p.191). O corpo próprio e seus poderes perceptivos deixam de ser o centro da análise filosófica para se tornar "o caso particular de um desvio, de uma diferenciação em todo lugar operante" (Haar 1, p.17). MerleauPonty reconheceria uma visibilidade ou uma sensibilidade latentes no próprio ser, as quais fundariam as funções ativas corporais. Em vez de centro e sustentáculo do espetáculo perceptivo, tal como aparecia na Fenomenologia da Percepção, o corpo se tornaria somente o ponto em que a sensibilidade latente ao ser se reuniria e se manifestaria para $\mathrm{si}^{2}$. Dessa maneira, em sua última filosofia, Merleau-Ponty defenderia a prioridade de uma sensibilidade anônima universal, exprimida na noção de "carne do mundo".

Essa seria, segundo Haar, uma tese bastante problemática. Para Haar, MerleauPonty pretende que o Ser sensível englobe "dimensões tão diferentes quanto a vida orgânica, a percepção, o pensamento e a linguagem” (Haar 1, p.22). Mas essa pretensão seria insustentável. Haar compreende "o campo 'universal' do Sensível", proposto por Merleau-Ponty, como o que "se doa à percepção" (Haar 1, p.10), definição que torna clara a insuficiência da ontologia final do filósofo. Afinal, "para ser universalizável, mesmo metafisicamente, o mundo percebido não deveria com efeito incluir todas as dimensões? Ora, salta aos olhos que ele não possui nem a História nem a Fala. A universalidade se torna desde então uma abstração metafísica" (Haar 1, p.33). Haar pretende assim ter desvelado o procedimento metafísico que viciaria, desde a base, a ontologia de MerleauPonty: pretende-se investigar o ser, pretende-se investigar o modo pelo qual todas as coisas e eventos são, mas considera-se somente o modo como certas coisas e eventos são, a saber, os fenômenos apreensíveis sensivelmente. Ao apresentar esse modo particular como geral, como incluindo as características de todo ser, deixa-se de apreender a 
especificidade de vários temas, cujo modo de ser permanece ignorado.

Mas terá Michel Haar razão em suas suspeitas? Será que Merleau-Ponty universaliza ingenuamente uma dimensão ôntica e a toma como ontológica? De fato, algumas afirmações do filósofo, tomadas isoladamente, podem realmente dar essa impressão a um leitor com um olhar heideggerianamente treinado. O título de uma nota de janeiro de 1959 por si só já causaria desconforto em tal leitor: "o Ser bruto ou selvagem (=mundo percebido)" (Merleau-Ponty 3, p.221). Mas é no corpo dessa nota que a confissão parece ocorrer. Ali, Merleau-Ponty afirma: “o mundo perceptivo amorfo de que eu falava em relação à pintura (...) é no fundo o Ser no sentido de Heidegger (...) e que aparece como contendo tudo o que será alguma vez dito, nos deixando entretanto a criá-lo" (Merleau-Ponty 3, p. 221-2). Aqui Merleau-Ponty parece assumir todos os pecados apontados por M. Haar: haveria a identificação do ser com o mundo sensível, o que implicaria acreditar ingenuamente que todas as dimensões ônticas (por exemplo, a linguagem) já estão contidas nesse mundo sensível.

Mas seria mesmo a empreitada final de Merleau-Ponty descaradamente uma metafísica? Para responder a essa pergunta, notemos que Haar parece apresentar uma definição bastante restrita do mundo ou do ser sensível: como vimos, para ele, tratase daquilo que se doa à percepção. Haar apresenta o sensível como conjunto de dados positivamente apreendidos pelos sentidos. Mas não é assim que os últimos textos de Merleau-Ponty consideram essa noção. Inspirado em alguns trechos de Idéias II, MerleauPonty, no artigo O Filósofo e sua Sombra, propõe a seguinte definição: “o sensível não é somente as coisas, mas também tudo o que aí se esboça, mesmo implicitamente, tudo o que aí deixa seu traço, tudo o que aí figura, mesmo a título de desvio [écart] e como uma certa ausência” (Merleau-Ponty 7, p.217). Quer dizer que o sensível não é um conjunto de dados positivos; há dimensões de negatividade que estariam incrustadas nos dados positivos. Assim, é necessário considerar certas ausências constitutivas ${ }^{3}$, que se doam somente enquanto ausência, para só então apresentar a dimensão sensível como universal, como verdadeira dimensão ontológica. É o que Merleau-Ponty faz por meio de sua noção de invisível. Ao considerar que há dimensões invisíveis que compõem a densidade do sensível, Merleau-Ponty amplia consideravelmente o escopo desse último. Sem levar em conta essa ampliação, fica fácil apresentar a investigação do ser bruto ou da carne como metafísica. No entanto, parece-me imprescindível apresentar como complementar à definição do ser bruto como mundo percebido a investigação das dimensões invisíveis que compõem a profundidade ontológica do sensível.

É por meio dessa noção de dimensões invisíveis que Merleau-Ponty pretendia incluir a história e a linguagem em sua análise ontológica4 ${ }^{4}$. Conforme reconhece MerleauPonty, "a linguagem, a arte, a história gravitam em torno do invisível (a idealidade)" (Merleau-Ponty 2, p.291). Assim, por exemplo, em relação à linguagem, diferentes enunciações particulares podem se pretender exemplos de uma "mesma" significação justamente por partilharem uma certa intenção comum, um certo modo idêntico de visar ou de se referir a tais e tais dados. Há aqui um caráter unificador da significação lingüística em relação à inesgotável riqueza de detalhes das situações vividas; a significação permite o reconhecimento do mesmo em experiências que, por sua complexidade, são sempre únicas. Desse ponto de vista, a linguagem, mais do que o conjunto das enunciações factuais, é uma matriz de ordenação da experiência, uma membrana inaparente por meio da qual a diversidade perceptível (quer dizer, mesmo aquela que ainda não se concretizou) do mundo se ordena em regiões ou espécies ${ }^{5}$. As significações lingüísticas são exemplos de “estruturas do vazio" (Merleau-Ponty 3, p.284, fev. 1960) que permeiam o sensível e que de seu próprio interior fazem emergir arranjos densos de fenômenos, que não se esgotam na pura positividade dos dados atuais. Essas estruturas não decorrem de um mundo espiritual autônomo, mas são a infra-estrutura da própria experiência do sensível ${ }^{6}$.

Assim, não é verdade que Merleau-Ponty injustificadamente se propôs a tratar a história e a linguagem por meio da análise daquilo que se doa à percepção (por meio de um "sensível" compreendido de maneira estreita). A ampliação daquilo que se considera âmbito de contato com o ser, conforme vimos na seção passada, mostra que Merleau-Ponty não pretende tratar a vida pública e privada, a ciência e a história como puros fenômenos percebidos, mas como eventos que, em sua dimensão ou nível próprio, explicitam estruturas ontológicas irredutíveis ao tema do "objeto percebido". Se em alguns textos Merleau-Ponty insiste em incluir todas essas dimensões no "sensível”, é porque, conforme já acentuamos, amplia a noção de sensível e não porque achata ou mutila a história ou a linguagem para tratá-las somente como fenômenos imediatamente percebidos. Podese questionar se Merleau-Ponty consegue manter a especificidade dessas dimensões ao 
considerá-las como membranas invisíveis no interior do ser sensível (questão para a qual o inacabamento de sua obra talvez nos impeça de dar qualquer resposta), mas não me parece correto ignorar que ao menos na intenção de seu projeto ontológico MerleauPonty buscou evitar uma ingênua hipóstase metafísica do sensível.

\section{IV}

Até aqui reavaliamos a obra de Merleau-Ponty segundo o critério proposto por Michel Haar, e chegamos a uma conclusão oposta a desse autor. Os esforços pela ampliação da noção de sensível, de maneira a nele incluir dimensões que só se doam como ausência, atestariam que Merleau-Ponty não hipostasia arbitrariamente uma região ôntica, mas busca conscientemente desvelar que toda amplitude ontológica já está contida no sensível. No entanto, justamente essa solução, quer dizer, o apelo a dimensões invisíveis parece comprometer Merleau-Ponty com uma empreitada metafísica, conforme passemos para a aplicação do segundo critério estabelecido por nós na primeira seção. Segundo esse critério, uma investigação filosófica se realiza de modo metafísico se desrespeita os limites cognitivos estabelecidos pelas estruturas subjetivas, as quais exigem uma experiência como base para a formulação de teses com valor epistêmico. Ao apresentar descrições de realidades que escapam a qualquer experiência possível, uma investigação filosófica ignoraria as restrições cognitivas impostas pela subjetividade e se caracterizaria então como metafísica. Ora, mas não é exatamente o que parece ocorrer com MerleauPonty? A fim de ampliar a noção de sensível, não apela ele a "realidades negativas" que não se doam diretamente à percepção, quer dizer, que não se tornam objetos de uma experiência possível? Afinal, o que significa afirmar que algo se doa como ausência, quer dizer, justamente como o que não se doa? Estaria Merleau-Ponty aqui meramente preso a jogos conceituais sem nenhum lastro com a experiência? Em suma, será que para salvar a complexidade do ser, sem achatá-lo numa dimensão ôntica ingenuamente hipostasiada, Merleau-Ponty ignora as restrições cognitivas da subjetividade?

Responderemos negativamente a essas duas últimas questões. Para tanto, importa mostrar, em primeiro lugar, que Merleau-Ponty reconhece algo semelhante ao critério kantiano proposto por nós, e que, assim, ele se preocupou com o problema dos limites cognitivos na formulação de sua ontologia. A fim de tornar visível essa preocupação, vamos nos remeter ao modo como o filósofo se apropria da intenção de autores designados como metafísicos (segundo o critério kantiano) para desenvolver sua própria reflexão. No curso A filosofia hoje, Merleau-Ponty apresenta sua ontologia como "metafísica no sentido clássico" (Merleau-Ponty 4, p.37), ou seja, como uma investigação que considera a totalidade do ser, e não somente domínios particulares (como se, por exemplo, a filosofia devesse investigar somente as significações lingüísticas, enquanto o âmbito dos fatos deveria ser tratado exclusivamente pelas ciências empíricas). Como metafísica no sentido clássico, Merleau-Ponty se refere aos autores do Grande Racionalismo do século XVII, com os quais já aprendera, conforme o artigo Em toda e em nenhuma parte, que não se deve limitar a investigação da realidade ao conhecimento científico (Cf. MerleauPonty 7, p.186). Em A filosofia hoje, Merleau-Ponty retoma explicitamente essa intenção abrangente do Grande Racionalismo, qual seja, de explicitar o ser em sua totalidade, o que supõe uma análise mais ampla que aquela oferecida pelos métodos científicos de verificação empírica. Aqui cabe perguntar se a retomada dessa intenção compromete Merleau-Ponty com teses acerca de realidades inalcançáveis pelos sentidos e que só poderiam ser descritas por uma pura concatenação lógica de conceitos.

A crença na possibilidade de um conhecimento para além de toda experiência possível, o que constituiria o núcleo propriamente metafísico do Grande Racionalismo, é claramente rejeitada por Merleau-Ponty. Ele afirma: “o que nos separa do século XVII, não é um decadência, é um progresso da consciência e da experiência" (Merleau-Ponty 7 , p.189). Nos séculos seguintes, teria ficado claro que o acordo entre as deduções lógicas e o mundo existente não é imediato ou evidente, e que não se pode pretender descrever realidades sem o lastro da experiência. Eis a lição kantiana que Merleau-Ponty assume como um progresso. Esse distanciamento em relação às teses metafísicas do Grande Racionalismo sugere-nos que Merleau-Ponty não se comprometeria com uma solução que assim pudesse ser qualificada. Desse modo, parece-nos que seu apelo às dimensões invisíveis que constituem a densidade ontológica do sensível deve de alguma forma responder à essa preocupação crítica reconhecida por ele mesmo como um progresso da reflexão. E de fato podemos explicitar tal preocupação se analisamos mais de perto a elaboração filosófica da noção de invisibilidade. 
No prefácio de Signes, Merleau-Ponty argumenta que uma das vantagens do par conceitual visível / invisível em relação ao par ser / nada é que não há uma oposição substancial ou de modo de ser entre os elementos do primeiro par como haveria naqueles do segundo (Cf. Merleau-Ponty 7, p.30). Dessa maneira, ao se tratar do invisível, não se pretende descrever realidades contrárias a ou absolutamente distintas daquelas sensíveis. O invisível é sempre invisível de algum visível, é sempre o avesso deste, e, neste sentido, está sempre relacionado àquilo que se doa positivamente na experiência. Com a noção de invisível, não se trata de circunscrever um tipo de ser substancialmente diferente do ser sensível, mas de considerar o sensível de modo mais amplo, incluindo suas dimensões que não se doam de maneira imediata e que se anunciam por sua falta, quer dizer, que se deixam suspeitar porque os dados positivos apontam para um negativo que também é constituinte do sentido da experiência.

Vemos assim que ao menos em sua delimitação conceitual a noção de invisível ou de dimensões negativas do ser não compromete Merleau-Ponty com realidades suprasensíveis, as quais são bastante criticáveis segundo o critério kantiano. Mas como a investigação filosófica poderá se aproximar dessas dimensões de negatividade? Como é possível tratar daquilo que na experiência só se marca como ausência? Certamente algumas dessas dimensões negativas são atestadas sem dificuldade em toda experiência que envolve enunciação lingüística ou contato inter-humano. Conforme mencionamos na seção anterior, as significações funcionam como uma membrana inaparente capaz de ordenar uma infinidade de episódios perceptivos. Essa virtude se estende para além dos episódios que efetivamente serão vividos pelos sujeitos falantes, pois mesmo situações possíveis que jamais se atualizarão podem ser, por meio da linguagem, classificadas e explicitadas em muitos dos seus componentes gerais. Além das estruturas significativas lingüísticas, a vida psíquica dos sujeitos também é uma dimensão que não se doa perceptivelmente. No entanto, não é necessário tomá-la como expressão de uma substância espiritual incompreensivelmente ligada à massa corporal; basta considerá-la, tal como sugere Merleau-Ponty, como uma dimensão sensível negativa, como um avesso invisível do corpo, o qual, ainda que ausente, sempre é levado em conta nas interações sociais (já que essas ocorrem entre pessoas, quer dizer, entre sujeitos complexos dotados de comportamento, de intenções, de sentimentos, de opiniões, etc. e não somente entre corpos visíveis). A linguagem e a vida psíquica são, assim, exemplos simples de dimensões invisíveis, e nos confirmam que longe de se referir a mirabolantes construções conceituais sobre um reino supra-sensível, Merleau-Ponty tenta por meio da noção de invisibilidade reformular o estatuto ontológico de componentes óbvios da experiência, os quais não deveriam ser concebidos como um tipo de ser separado do sensível, mas como camadas ou níveis no interior desse último.

Devemos acentuar, no entanto, que a noção de invisibilidade não se esgota nos componentes significativos ou psíquicos da experiência subjetiva (e que podem ser atestados facilmente por qualquer um em sua experiência). Por meio dessa noção, Merleau-Ponty pretende qualificar regiões do próprio ser e não somente dimensões ligadas à subjetividade. É o que fica claro, por exemplo, nos cursos sobre a natureza. Ali Merleau-Ponty usa a noção de invisível para se referir à infra-estrutura inaparente que torna possível a auto-organização dos organismos: “encontra-se então um núcleo de fenômenos, um recobrimento lateral dos microfenômenos um no outro, uma coesão em torno do ser invisível (...) que eles envolvem, em torno do qual eles se enrolam, cristalizam o Gestalthafte" (Merleau-Ponty 2, p.303). Merleau-Ponty se refere aqui ao desenvolvimento dos embriões, tema que exploraremos com mais detalhes logo a seguir, e denomina de invisível os processos pelos quais o próprio ser dos embriões se molda. Importa agora somente notar que o invisível também se refere a dimensões inerentes ao próprio ser do mundo ou da vida em geral. É principalmente em relação a essas regiões invisíveis independentes da subjetividade que surge com toda força a dificuldade mencionada acima: como é possível investigar aquilo que excede o que se doa diretamente na experiência sem cair num discurso metafísico? Parece-me que a resposta a essa questão está no desenvolvimento de um método indireto para a ontologia. Numa nota de fevereiro de 1959, Merleau-Ponty afirma: "não se pode fazer ontologia direta. Meu método 'indireto' (o ser nos entes) é o único conforme o ser” (Merleau-Ponty 3, p.231). O autor parece entender por ontologia direta os resultados descritivos seja de experiências particulares vividas, seja de construções lingüístico-conceituais apresentadas como caracterização de realidades ou mesmo do ser em geral. Assim, se um filósofo se baseia apenas em suas vivências para descrever ou caracterizar o ser em geral, ou se ele propõe, sem nenhuma comprovação por alguma instância externa, que certo conjunto de 
categorias articulados de tal maneira descreve o ser, então se trataria de ontologia direta. E a ontologia direta corre o risco seja de se limitar injustificadamente a certos aspectos do ser (no caso da descrição de vivências particulares), seja de se limitar a construções conceituais abstratas, que não correspondem à verdadeira estrutura do ser. Daí que a ontologia, para ser conforme o ser, deva ser indireta.

Mas de que maneira se desenvolve indiretamente uma ontologia? MerleauPonty nos adverte que só é possível chegar ao ser por meio do seres ou entes, ou seja, que é imprescindível investigar certos domínios ônticos para que determinadas características ontológicas se façam notar. É exatamente por isso que Merleau-Ponty analisa a ciência, a pintura, a literatura e mesmo alguns fatos históricos em seus cursos e textos finais. Ele crê que as atividades e disciplinas não-filosóficas contemporâneas estão em contato com o ser bruto que a filosofia deveria explicitar. Assim, é a análise dos resultados dessas atividades e disciplinas que permite explicitar como tese filosófica positiva as características das dimensões de negatividade constituintes do ser. É então o apelo a tais disciplinas que garante o "lastro de experiência" para a noção geral de invisibilidade, e impede que ela seja um mero constructo metafísico: a filosofia só tem acesso à invisibilidade constitutiva do mundo indiretamente, por meio do modo como ela é explicitada nas disciplinas e atividades não-filosóficas.

Consideremos como exemplo de análise ontológica indireta o apelo de MerleauPonty a alguns temas estudados pela ciência. "Ao interrogar a ciência", crê o autor, "a filosofia chegará a encontrar certas articulações do ser que lhe seria mais difícil de descobrir de outro modo" (Merleau-Ponty 6, p.118). Tomemos como caso emblemático o estudo da embriologia, do qual Merleau-Ponty se serve em seu segundo curso sobre a natureza (1957-8). Por meio de diversas pesquisas nessa área, as quais supõem complexas técnicas de coleta e mensuração para constituir o próprio dado científico (ou seja, o dado não é um fenômeno disponível à percepção ingênua), pôde-se desvelar uma certa inteligibilidade da organização celular nos embriões, anterior ao desenvolvimento do controle neuronal. Para explicar essa inteligibilidade anterior à maturação neural, Merleau-Ponty se refere à noção de gradientes, cunhada por Coghill: diferentes níveis de suscetibilidade dos tecidos embrionários a impulsos elétricos ou bioquímicos (Cf. Merleau-Ponty 2, p.191). Por meio desses gradientes, surgem oposições morfológicas embrionárias entre um pólo vegetativo ou posterior e um pólo animal ou anterior. Em seguida, distribuem-se certas funções correlacionadas com tais pólos morfológicos, o que torna possível a manifestação de certos comportamentos embrionários pré-neurais. Tais comportamentos estão inscritos em fases da morfogênese embrionária prévias ao funcionamento das estruturas fisiológicas que normalmente os possibilitariam ${ }^{7}$. Merleau-Ponty explora esse resultado como explicitação de uma produtividade inscrita na própria natureza, e que parece rejeitar todo tipo de direcionamento espiritual ou intelectual, sem com isso deixar de estabelecer uma ordem, uma organização nos fatos. Por sua vez, essa ordem se antecipa à maturação de estruturas fisiológicas determinadas, o que parece implicar que a ordenação geral do comportamento embrionário não se esgota no mero funcionamento das estruturas fisiológicas atuais, mas supõe uma referência a uma totalidade futura ainda ausente. Assim, os estudos da embriologia legitimam a rejeição de concepções da reprodução animal que sejam finalistas (pois seria possível compreender pela mera ordenação interna aos gradientes bioquímicos a organização da vida, sem apelar para uma finalidade última) ou mecanicistas (pois as possibilidades futuras compõem o desenvolvimento embrionário, o qual não se reduz então a relações mecânicas entre as partes atuais do embrião). Dessa maneira, duas concepções ontológicas clássicas são rejeitadas, o que abre caminho para a exploração filosófica renovada do ser da natureza.

A abertura desse caminho provavelmente não seria possível sem o apelo às pesquisas científicas. Não seria possível excluir nenhuma concepção acerca do desenvolvimento embrionário sem o desenvolvimento das técnicas científicas contemporâneas de coleta de dados e de avaliação de hipóteses nessa área. Dessa maneira, a embriologia é um bom exemplo para clarificar por que a filosofia deve recorrer aos domínios ônticos para formular uma doutrina geral acerca do ser: é necessário considerar os dados fornecidos pelas disciplinas e atividades não-filosóficas a fim de constituir um modo justificado de incluir na reflexão ontológica domínios que escapam à observação direta. Assim, o apelo às disciplinas não-filosóficas mantém o lastro com a experiência e garante à filosofia, quando for extrair conseqüências ontológicas de domínios que escapam à experiência direta, o respeito às condições subjetivas do conhecimento. 


\section{REFERÊNCIAS BIBLIOGRÁFICAS}

1. HAAR, M. La Philosophie Française entre Phénoménologie et Métaphysique. Paris: PUF, 1999.

2. MERLEAU-PONTY, M. La Nature. Notes. Cours du Collège de France. Paris: Seuil, 1995.

3._. Le Visible et le Invisible. Paris: Gallimard, col. Tel, 2001.

4._. Notes de Cours 1959-1961. Paris: Gallimard, 1996.

5._._. Phénoménologie de la Perception. Paris: Gallimard, col. Tel, 1997.

6._._. Résumés de Cours. Collège de France 1952-1960. Paris: Gallimard, 1968.

7. . Signes. Paris: Gallimard, 1960.

8. SAINT AUBERT, E. Vers une Ontologie Indirecte. Sources et enjeux critiques de l'appel à l'ontologie chez Merleau-Ponty. Paris: Vrin, 2006.

\section{Merleau-Ponty: between ontology and metaphysics}

Abstract, In this article, we resume Michel Haar's evaluation according to which Merleau-Ponty's ontological project would redound to metaphysics. In order to make such an evaluation more rigorous, we propose another criterion, inspired by Kant, according to which Merleau-Ponty's work could also be classified as metaphysical. After that, we elucidate Merleau-Ponty's philosophical strategies on the basis of which we judge that neither according to Haar's criterion nor according to the Kantian's criterion constitutes Merleau-Ponty a metaphysical discourse.

Keywords: ontology, metaphysics, Merleau-Ponty, Michel Haar, Heidegger.

\section{NOTAS}

1. Segundo Saint Aubert (que recenseou cuidadosamente o uso de certos termos por Merleau-Ponty), o filósofo se refere de modo sistemático ao seu próprio projeto como ontológico somente a partir de 1957. Cf. Saint Aubert 8, introdução.

2. Segundo a Fenomenologia, "o corpo próprio está no mundo como o coração no organismo: ele mantém continuamente em vida o espetáculo visível, ele o anima e o nutre interiormente, e forma com ele um sistema" (Merleau-Ponty 5, p.235). Quer dizer que os aspectos sensíveis do mundo só se ordenam em função da atividade corporal, a qual condiciona a própria existência dos espetáculos visíveis. Já em $O$ Visível e o Invisível, Merleau-Ponty assume a tarefa de "descrever o visivel como algo que se realiza por meio do homem, mas que não é absolutamente antropológico" (Merleau-Ponty 3, p.322, março
1961).

3. 'Não considerar o invisível como um outro visível 'possível', ou um 'possível' visível para um outro (...). O invisível está ai sem ser objeto, é a transcendência pura, sem máscara ôntica" (Merleau-Ponty 3, p.278, jan. 1960).

4. "Pôr a questão: a vida invisível, a comunidade invisível, outrem invisível, a cultura invisível" (Merleau-Ponty 3, p.278, jan. 1960).

5. "A idéia é esse nível, essa dimensão, não portanto um invisível de fato, como um objeto escondido atrás de um outro, e não um invisível absoluto, que nada teria a ver com o visível, mas o invisível desse mundo, aquele que o habita, o sustenta e o torna visível, sua possibilidade interior e própria, o Ser desse ente" (Merleau-Ponty 3, p.196).

6. "Não há que buscar coisas espirituais; existem apenas estruturas do vazio [do invisível] - simplesmente quero plantar esse vazio no Ser visível, mostrar que ele é seu avesso - em particular, o avesso da linguagem" (Merleau-Ponty 3, p.284, fev. 1960).

7. Por exemplo, o feto humano, antes mesmo de dispor de sistemas neurais que coordenam os batimentos cardíacos, apresenta, em algumas situações (ao menos após nove semanas e meia de gestação), sinais cardíacos que se assemelham àqueles de adultos (Cf. MerleauPonty 2, p.197). 